\title{
GEOLOGIA DE CALCÁRIOS DO TOCANTINS E COMPOSIÇÃO QUÍMICA DE LATOSSOLOS E NEOSSOLOS QUARTZARÊNICOS
}

\section{GEOLOGY OF TOCANTINS LIMESTONES AND CHEMICAL COMPOSITION OF LATOSOLS AND QUARTZARENIC NEOSOLS}

João Vidal de Negreiros Neto', Rubens Ribeiro da Silva², Gilson Araújo de Freitas $^{3}$, Antônio Clementino dos Santos ${ }^{4}$

\section{RESUMO}

Com a crescente demanda por insumos, o calcário é parte importante dos requerimentos para produção agropecuária. Assim, objetivou-se com esta revisão caracterizar os aspectos gerais de Latossolos e Neossolos Quartzarênicos e da geologia de calcários do estado do Tocantins. A partir de levantamentos de pesquisas realizadas com Latossolos e Neossolos Quartzarênicos no Tocantins, que representam mais de $48 \%$ da superfície total do Estado, chega-se a uma definição média de fertilidade, com potencial de elevação da produtividade a partir do uso de tecnologias, como a calagem. As jazidas de rochas calcárias estão distribuídas de norte ao sul do Estado. Dentre elas, destacam-se a jazida de rochas sedimentar e metamórfica na região sudeste (Natividade e Dianópolis), com PRNT de 75\%. A jazida de calcários de rocha metamórfica na região noroeste (Xambioá, Bandeirantes e Bernardo Sayao). E a jazida de origem metamórfica na região centro-oeste (Lagoa da confusão) e sudoeste (formoso do Araguaia). Dessa forma, os Latossolos e Neossolos Quartzarênicos, que naturalmente são ácidos, tem grande probabilidade de ter uma jazida de rocha calcária nas proximidades, devido a distribuição de norte a sul destas jazidas no Tocantins.

Palavras-chave: Rocha calcária. Latossolo. Neossolo Quartzarênico.

\section{ABSTRACT}

With an increasing demand for inputs, footwear is an important part of the requirements for agricultural production. The objective was to review the general characteristics of Latosols and Neosols Quartz and Geological Calculus of the State of Tocantins. Based on surveys of Latosols and Quartzarenic Neosols in Tocantins, which represent more than $48 \%$ of the total area of the State, an average of fertility classification is reached, with the potential to increase productivity through the use of technologies, like a liming. The deposits of limestone rocks are distributed in the northern southern part of the state. Among them, the sedimentary and metamorphic rocks in the southeast region (Natividade and Dianópolis), with PRNT of $75 \%$, stand out. The metamorphic rock limestone deposits in the northwest region (Xambioá, Bandeirantes and Bernardo Sayao). And the mine of metamorphic origin in the center-west and southwest (beautiful of Araguaia). Latently, the Latosols and the Quartzarenic Neosols, which are important, are very likely to have a limestone rock nearby due to a South American distribution of deposits in the Tocantins.

Keywords: Limestone rock. Oxisols. Quartzarenic Neosol.
1 Professor Adjunto do curso de curso de Zootecnia da UFT Campus Araguaína, Araguaína TO, Brasil.

2 Engenheiro Agrônomo, Doutor em Solos e Nutrição de plantas, Professor da Universidade Federal do Tocantins, UFT, Gurupi-TO, Brasil.

${ }^{3}$ Engenheiro Agrônomo, Doutor em Produção Vegetal, PNPD do Programa Pós-Graduação em Produção Vegetal/Universidade Federal do Tocantins, Gurupi-TO, Brasil, $\quad$ E-mail: araujoagro@hotmail.com

${ }^{4}$ Engenheiro Agrônomo, Prof. Dr. Adjunto III do Curso de Zootecnia. Bolsista de Produtividade CNPq. Câmpus de Araguaina/UFT. Tocantins, TO Brasil. 


\section{INTRODUÇAO}

Apesar de geograficamente pertencer à região Norte do Brasil, o estado do Tocantins encontra-se em área de ecótono Cerrado/Floresta Amazônica. Assim, dos cinco biomas brasileiros, o Tocantins apresenta dois: Savana e Floresta Ombrófila. Parte das propriedades e características dos solos explica a cobertura vegetal de uma região. No Cerrado e em parte das Florestas Ombrófilas as plantas apresentam maior tolerância ao caráter tóxico de alumínio e são adaptadas a solos lixiviados.

O conhecimento das características do solo e das classes de solos onde a produção agrícola e pecuária são mais intensas é necessário para a recomendação de tecnologias para incrementar a produtividade.

O Estado do Tocantins apresenta 10 classes de solos (IBGE, 2007a), dos quais Latossolos e Neossolos Quartzarênicos, que abrangem mais de 40,4\% do território do estado, e compõem os solos com maior uso intensivo e potencial para exploração (SEPLAN, 2007).

No bioma Amazônia predominam solos altamente intemperizados com limitações químicas, mas não físicas, ao crescimento de plantas cultivadas (RODRIGUES, 1996). Entre os atributos químicos que restringem a produtividade, está elevada acidez do solo (GAMA et al., 2007), associada ao alumínio tóxico e baixos teores de cálcio e magnésio.

A intensificação de uso dos solos de cerrado e da região amazônica só é possível com a adoção de técnicas de correção da acidez, o que pode ser realizado por meio do conhecimento das características químicas e de suas reações no interior dos solos.

O conhecimento dos atributos do calcário utilizado, como sua origem, teores oxídicos de cálcio, magnésio, silício, ferro e alumínio, bem como, o seu poder de neutralização (PN), contribuem para minorar os erros decorrentes das recomendações de corretivos da acidez do solo.

O objetivo desta revisão bibliográfica é apresentar resultados de trabalhos de pesquisas em Latossolos e Neossolos Quartzarênicos e apresentar o panorama de ocorrência de jazidas de calcário e quais estão sendo exploradas.

\section{MATERIAIS E METODOS}

Realizou-se uma busca artigos científicos nos idiomas português e inglês, em periódicos nacionais e internacionais nas bases eletrônicas de dados: Scielo, Spell e Web of Science, entre os dias 06 de agosto a 24 de novembro de 2018. Foram definidas em 
função da disponibilidade de consulta e relevância, no qual destaca-se Spell por se tratar de uma base nacional consolidada, Scielo pela diversidade de periódicos nacionais e internacionais indexados, e Web of Science, por configurar-se como uma das principais bases de pesquisas no cenário internacional.

Considerando as diferenças entre as bases pesquisadas, foram utilizadas as palavras chaves no idioma inglês "limestone pedology", " limestone geology", "limestone rocks in Tocantins", "latosols in Tocantins" e "Neurosols Quartzarênicos in Tocantins", na base Web Of Science, e os termos "pedologia de calcários", "geologia de calcários", "rochas calcárias no Tocantins", "latossolos no Tocantins" e "Neossolos Quartzarênicos no Tocantins" nas bases nacionais Spell, Scielo. As respectivas palavras foram empregadas nas buscas, por englobar as principais expressões objeto de investigação do presente estudo. Foram dados prioridade para artigos científicos.

\section{REVISAO DE LITERATURA}

\subsection{SOLOS DO TOCANTINS}

O Estado do Tocantins está localizado na região central brasileira, apresentando áreas de ecótonos, principalmente, Floresta Estacional/Cerrado (HAIDAR et al., 2013; MENDONÇA, 2012; TAVARES \& CANDEIRO, 2012). As classes de solos encontradas no Estado e apresentadas na Tabela 1 mostram a predominância de Plintossolos, com mais de um terço de toda superfície de solos, representados por três classes no segundo nível categórico (Pétrico, Argilúvico e Háplico) e com abrangência de extensas áreas nas porções Oeste, Centro-Sul e Sudoeste do Estado.

Tabela 1. Classes de solos encontradas no estado do Tocantins (adaptado do IBGE, 2007a)

\begin{tabular}{lcc}
\hline \multicolumn{1}{c}{ Classe de solo } & Área $\left.\mathbf{( k m}^{2}\right)$ & Área $(\%)$ \\
\hline Plintossolos Pétricos (FF)/Argilúvicos (FT)/ Háplicos (FX) & $93.393,58$ & 33,65 \\
Neossolos Litólicos (RL)/Flúvicos (RY)/Quartzarênicos (RQ) & $75.669,08$ & 27,26 \\
Latossolos Amarelos (LA)/Vermelhos (LV)/Vermelho-Amarelos (LVA) & $59.765,23$ & 21,53 \\
Argissolos Amarelos (PA)/Vermelhos/(PV)/Vermelho-Amarelos (PVA) & $28.039,70$ & 10,10 \\
Gleissolos Háplicos (GX) & $14.158,60$ & 5,10 \\
Cambissolos Háplicos (CX) & $4.164,40$ & 1,50 \\
Luvissolo Háplicos (TX) & $1.237,21$ & 0,45 \\
Nitossolos Vermelhos (NV) & 970,37 & 0,35
\end{tabular}




\begin{tabular}{lcc} 
Planossolos Nátricos (SN)/Háplicos (SX) & 100,42 & 0,04 \\
Chernossolo Argilúvicos (MT) & 40,96 & 0,01 \\
Dunas & 2,28 & 0,001 \\
\hline
\end{tabular}

Fonte: adaptado de IBGE, 2007

(http://www.visualizador.inde.gov.br/VisualizaCamada/43)

Os Neossolos representam a segunda classe de solos de maior ocorrência no estado do Tocantins, com 27,26\% do total, com três subordens (Litólico, Flúvico e Quartzarênico), dos quais 18,9\% são Quartzarênicos (COLLICHIO, 2008). Os Neossolos abrangem extensas áreas, desde o extremo Norte do estado, passando pelo Centro, até o Sudeste e Leste.

A terceira classe em predominância é composta pelos Latossolos, encontrados nas subordens Amarelos, Vermelhos e Vermelho-Amarelos. Os Latossolos se caracterizam pela presença de manchas esparsas nas porções Central e Norte e áreas contínuas mais extensas no Sul do estado. Os Argissolos Amarelos, Vermelhos e Vermelho-Amarelos, com $10,10 \%$ da área total de solos representam a quarta maior classe, ocorrendo em áreas do Noroeste e do Sul/Suldeste. Em seguida vem os Gleissolos Háplicos com 5,10\%. Estas classes de solos ocorrem em maior área no Sudoeste, nas regiões de várzeas formadas na bacia do Araguaia. As outras seis classes de solos somam 2,35\% (IBGE, 2007a).

Neossolos Quartzarênicos e Latossolos são as classes de solos com importância na produção de grãos e na pecuária tocantinense. Somados, esses solos representam mais de $40 \%$ da área total do Estado, os quais, bem manejados, podem elevar a produção agropecuária.

Trabalhos de pesquisa e revisões que abordam a etnopedologia (ARAÚJO et al., 2013; AUDEH et al., 2011; VALE JÚNIOR et al., 2007) e "consciência pedológica" (MUGGLER et al., 2006) vêm crescendo em termos de publicações (BARRERA-BASSOLS \& ZINCK 2003). O conhecimento dos solos de uma localidade, município, estado ou nação, permitem o entendimento de valores sociais e culturais de um povo (AMARAL et al., 2013; MATOS et al., 2014; TAVARES, 2012).

\subsubsection{Latossolos}

O conceito de Latossolo, quando foi lançado pelo pedólogo americano Kellog (1949), em uma conferência americana sobre classificação de solos, que aconteceu em Washington (SÉGALEN, 1994), identificava características de solos altamente 
intemperizados e intensamente lixiviados, transformando-os em solos com baixas atividades das argilas e capacidade de troca de cátions. Soma-se a estas características, o fato de apresentarem colorações homogêneas, com matizes entre avermelhadas e amareladas, serem profundos - de $200 \mathrm{~cm}$ a $300 \mathrm{~cm}$, quando, neste caso o horizonte A apresentar mais de $150 \mathrm{~cm}$ de espessura (EMBRAPA, 2006) - com argila uniformemente distribuída nas camadas do perfil, agregados estáveis e baixo conteúdo de silte em relação à argila. Entretanto, informações quantitativas não faziam parte da caracterização dessa classe de solos. Os Latossolos são solos constituídos por material mineral, que apresentam horizonte B latossólico imediatamente abaixo de qualquer horizonte diagnóstico superficial, exceto o hístico.

A baixa capacidade de retenção de nutrientes está relacionada ao elevado estágio de intemperização, que contribui com a baixa capacidade de troca de cátions. Os Latossolos se desenvolvem sob condições de relevo plano a suave ondulado (FERREIRA, 2008; OLIVEIRA, 2009). A grande limitação desses solos, que compõem grande parte dos solos tropicais, é a baixa fertilidade natural associada à elevada acidez, passíveis de correção com práticas de manejo adequadas. O emprego destas tecnologias foi responsável pela expansão das áreas agrícolas no cerrado brasileiro (PRADO, 2007).

Os Latossolos apresentam razoável resistência a erosão de superfície, em virtude da elevada permeabilidade, condição esta, influenciada pela elevada porosidade e homogeneidade na estruturação por todo perfil. Apresentam textura variável e as áreas de superfícies geomórficas mais antigas de uma dada região, em geral, são formadas por latossolos (SOUZA, 2012).

O estado do Tocantins apresenta $21,53 \%$ das áreas compostas pela ordem Latossolos, abrangendo do extremo norte ao sul. É nessa classe de solos em que a agricultura e a pecuária ocorrem com maior uso intensivo, com culturas de ciclos curto e longo, e pastagens com estágios avançados de degradação (COLLICCHIO, 2008).

Trabalhos de pesquisas demonstram a amplitude nos valores de fertilidade desses solos (Tabela 2). Os valores de $\mathrm{Ca}+\mathrm{Mg}, \mathrm{Al}, \mathrm{H}+\mathrm{Al}, \mathrm{V} \%$ e $\mathrm{pH}$ da maioria dos trabalhos levantados, não representa a fertilidade original dos Latossolos do estado, uma vez tais atributos químicos foram determinados a partir de áreas com mais de um ciclo de cultivo ou áreas utilizadas para experimentação, com adição de corretivos e fertilizantes. Entretanto, é possível detectar que as médias dos valores estão aquém dos limites adequados para a maioria das plantas cultivadas (CFSEMG, 1999). 
Tabela 2. Análises químicas de Latossolos do Estado do Tocantins.

\begin{tabular}{|c|c|c|c|c|c|c|c|c|c|}
\hline \multirow{2}{*}{ Fonte } & $\mathrm{Ca}+\mathrm{Mg}$ & $\mathrm{Al}$ & $\mathrm{H}+\mathrm{Al}$ & $\mathrm{K}$ & $(\mathrm{t})$ & \multirow{2}{*}{$\frac{P}{m^{2 d m^{-3}}}$} & $\mathrm{v}$ & MO & $\mathrm{pH}$ \\
\hline & \multicolumn{5}{|c|}{$\mathrm{cmol}_{\mathrm{c}} \mathrm{dm}^{-3}$} & & $\%$ & $\%$ & $\mathrm{H}_{2} \mathrm{O}$ \\
\hline SABOYA et al., 2012 & 3,7 & 0,1 & 2,5 & 0,2 & 6,3 & 90,0 & 60,9 & 5,0 & 5,8 \\
\hline SILVA et al., 2012 & 4,0 & 0,0 & 1,0 & 0,2 & 4,1 & 15,5 & 78,9 & - & 6,3 \\
\hline CAPONE et al., 2012 & 2,5 & - & 5,2 & 0,1 & - & 10,2 & 38,8 & 1,5 & 5,4 \\
\hline FLORES et al., 2013 & 3,2 & 0,0 & - & 0,2 & - & 14,0 & - & 1,8 & 5,8 \\
\hline COELHO et al., 2013 & 2,2 & 0,0 & 1,6 & 0,1 & 2,3 & 3,0 & 58,7 & 1,7 & $4,9^{1}$ \\
\hline FAGERIA et al., 2010 & 0,8 & 0,4 & - & 0,1 & 1,3 & 0,8 & - & 0,9 & 5,3 \\
\hline NEGREIROS NETO et al., 2014 & 3,3 & - & 2,3 & 0,2 & - & 15,7 & 60,6 & 2,0 & 5,9 \\
\hline ROTILI, 2009 & 1,3 & - & 2,9 & 0,1 & - & 2,4 & 32,6 & 0,2 & $4,3^{1}$ \\
\hline MARCELINO e CORRÊA, 2010 & 1,2 & 0,6 & 4,2 & 0,1 & 1,9 & 8,3 & 5,5 & 1,5 & 5,2 \\
\hline VILELA et al., 2010 & 2,0 & 2,2 & 8,8 & 0,2 & 4,2 & - & 40,0 & - & $3,8^{1}$ \\
\hline SANTANA et al., 2010 & 0,7 & 1,3 & 10,7 & 0,2 & 2,2 & 1,6 & 7,7 & 6,9 & 5,5 \\
\hline MATA et al., 2011 & 0,1 & 0,1 & 2,3 & 0,1 & 0,2 & 0,3 & 4,9 & 1,1 & 5,0 \\
\hline Média & 2,1 & 0,5 & 4,2 & 0,2 & 2,8 & 14,3 & 38,8 & 2,4 & 5,3 \\
\hline
\end{tabular}

${ }_{1}^{1} \mathrm{pH}$ em CaCl2

\subsubsection{Neossolos Quartzarênicos}

Os Neossolos Quartzarênicos, conceitualmente, apresentam textura arenosa até a profundidade mínima de $150 \mathrm{~cm}$ ou até que atinja uma camada lítica, exceto quando essa profundidade não seja inferior a $50 \mathrm{~cm}$. Os minerais quartzo, calcedônia e opala predominam em $95 \%$ da fração areia, sendo praticamente impossível encontrar minerais primários alteráveis.

As principais limitações estão relacionadas ao armazenamento de água e nutrientes. A presença de quartzo na constituição da porção mineral desses solos os torna praticamente desprovidos de reserva potencial de nutrientes e capacidade de troca catiônica (CTC). Essa função é transferida para a porção orgânica do solo. Com isso, o manejo no sistema plantio direto (SPD) tem grande importância nessa ordem de solos, quando utilizados para agricultura, uma vez que o risco de estresse hídrico nos pequenos veranicos os faz reduzir produtividade (SÁ, 2007).

As áreas de Neossolos Quartzarênicos no estado do Tocantins são contíguas e extensas, predominando nas porções Norte e Leste. Estudo realizado por COLLIER \& ARAÚJO (2010) com Neossolo Quartzarênico do município de Esperantina, no extremo norte do estado, em área cultivada em sistema agroflorestal (SAF), mata nativa e lavoura de subsistência, evidenciou que a matéria orgânica nos três sistemas se equiparam, mas os teores de P na mata $\left(7,1 \mathrm{mg} \mathrm{dm}^{-3}\right)$ diferem $(p<0,05)$ do SAF e da lavoura $(4,3$ e $5,3 \mathrm{mg}$ 
$\mathrm{dm}^{-3}$, respectivamente). Os teores de $\mathrm{K}$ na lavoura $\left(44,9 \mathrm{mg} \mathrm{dm}^{-3}\right)$ diferem de SAF e Mata ( 28,6 e 21,8 $\mathrm{mg} \mathrm{dm}^{-3}$, respectivamente), ocasionado pelas queimadas. Os teores de $\mathrm{Ca}+\mathrm{Mg}$ da Mata (27,6 mg dm³) e lavoura (24,6 mg dm-3) são superiores aos de SAF (14,1 mg dm$\left.{ }^{3}\right)$. Esses autores constataram, ainda, que os teores de $\mathrm{Al}$ trocável e acidez potencial $(\mathrm{H}+\mathrm{Al})$ são superiores no SAF, quando comparados à lavoura e mata. A velocidade de decomposição em solos arenosos, como são os Neossolos Quartzarênicos podem ter efeito na elevação da acidez potencial (RHEINHEIMER et al., 1998).

SANTANA et al. (2010) estudou transecto com 7 perfis pedológicos na região central do estado do Tocantins. Entre os solos estudados dois Neossolos Quartzarênicos fizeram parte (Tabela 3).

Tabela 3. Resultados das análises químicas de 2 perfis de Neossolos Quartzarênicos (adaptado de Santana et al, 2010)

\begin{tabular}{|c|c|c|c|c|c|c|c|c|c|}
\hline & $\mathrm{Ca}+\mathrm{Mg}$ & $\mathrm{Al}$ & $\mathrm{H}+\mathrm{Al}$ & $\mathrm{K}$ & $(\mathrm{t})$ & $\underline{P}$ & V & MO & $\mathrm{pH}$ \\
\hline Fonte & \multicolumn{5}{|c|}{$\mathrm{cmol}_{\mathrm{c}} \mathrm{dm}^{-3}$} & $\mathrm{mg} \mathrm{dm}^{-3}$ & $\%$ & $\%$ & $\mathrm{H}_{2} \mathrm{O}$ \\
\hline SANTANA et al., 2010 & 0,6 & 0,2 & 1,7 & 0,5 & 1,3 & 3,9 & 39,9 & 6,6 & 5,9 \\
\hline
\end{tabular}

O Neossolo Quartzarênico nos estudos de Negreiros Neto et al. (2010) e Melo et al. (2009) foi o mesmo, entretanto os primeiros autores realizaram os trabalhos no período de dezembro de 2006 a março de 2007, quando a área recebeu os primeiros manejos de fertilidade (Tabela 4). Em 2008, após dois ciclos de cultivos experimentais na mesma área Melo et al. (2009) fez análise do solo, resultando em elevação dos indicadores de fertilidade do solo, ressaltando a elevação de $2,9 \mathrm{cmol}_{\mathrm{c}} \mathrm{dm}^{-3}$ nos teores de Ca+Mg e $\mathrm{P}$ disponível, com o incremento de $1,1 \mathrm{mg} \mathrm{dm}^{-1}$. A saturação por bases do solo sofreu aumento de 22,8 $\%$, principalmente pela adição de calcário por dois anos consecutivos, mostrando que Neossolos Quartzarênicos, apesar da baixa capacidade de reter cargas, consegue elevar seu potencial produtivo com o manejo adequado.

Tabela 4. Resultados de análises químicas de Neossolos Quartzarênicos no estado do Tocantins 


\begin{tabular}{|c|c|c|c|c|c|c|c|c|c|}
\hline \multirow{2}{*}{ Fonte } & $\mathrm{Ca}+\mathrm{Mg}$ & $\mathrm{Al}$ & $\mathrm{H}+\mathrm{Al}$ & $\mathrm{K}$ & $(\mathrm{t})$ & \multirow{2}{*}{$\begin{array}{c}\underline{P} \\
m g d m^{-3}\end{array}$} & $\mathrm{~V}$ & $\mathrm{MO}$ & $\mathrm{pH}$ \\
\hline & \multicolumn{5}{|c|}{$\mathrm{cmol}_{\mathrm{c}} \mathrm{dm}^{-3}$} & & $\%$ & $\%$ & $\mathrm{H}_{2} \mathrm{O}$ \\
\hline NEGREIROS NETO et al., 2014 & 1,2 & 0,2 & 2,2 & 0,1 & 1,5 & 2,3 & 42,9 & 1,4 & $4,2^{1}$ \\
\hline Santana et al., 2010 & 0,6 & 0,2 & 1,7 & 0,5 & 1,3 & 3,9 & 39,9 & 0,7 & 5,9 \\
\hline SILVA et al., 2010 & 0,3 & 0,3 & 2,2 & 0,1 & 0,5 & 0,2 & 15,4 & 1,0 & $4,0^{1}$ \\
\hline NEGREIROS NETO et al., 2010 & 1,2 & 0,2 & 2,2 & 0,1 & 1,5 & 2,3 & 37,1 & 1,4 & $4,2^{1}$ \\
\hline MELO et al., 2009 & 3,1 & 0,5 & 2,5 & 0,1 & 4,3 & 3,4 & 60,3 & 1,0 & 5,5 \\
\hline Média & 1,3 & 0,3 & 2,16 & 0,2 & 1,8 & 2,4 & 39,1 & 1,1 & 4,8 \\
\hline
\end{tabular}

${ }^{1} \mathrm{pH}$ em $\mathrm{CaCl} 2$

\subsection{GEOLOGIA DO CALCÁRIO NO TOCANTINS}

Levantamento geológico no Estado (IBGE, 2007b), que indicam as zonas de ocorrência de minerais e rochas dominantes, apresentam formações com calcários e dolomitos na composição, além de outros minerais. Entretanto, alguns destaques devem ser dados, como a ocorrência de calcários metamórficos no noroeste do Estado, com jazidas em exploração nos municípios de Xambioá, Bernardo Sayão e Bandeirantes (Formação Xambioá - Grupo Estrondo). Em Xambioá empresa que explora calcário tem dois registros para comercializar calcários com garantias de 32,6\% e 38,5\% de $\mathrm{CaO}, 15,5 \%$ e $16,6 \%$ de $\mathrm{MgO}$, PN de $87 \%$ e $97 \%$ e PRNT de $86 \%$ e $87 \%$. E em Bernardo Sayão e Bandeirantes a empresa comercializa apenas calcário dolomítico, com registro para comercializar calcário com as mesmas garantias em ambas as unidades, sendo $27 \%$ de $\mathrm{CaO}, 16 \%$ de $\mathrm{MgO}, 100 \%$ PN e $88 \%$ PRNT.

Há uma ocorrência de calcário sedimentar no município de Guaraí, pertencente a formação geológica Pedra de Fogo, do Grupo Balsas. Entretanto, essa formação dispõe de calcários com baixos teores de $\mathrm{CaO}$ e $\mathrm{MgO}$, além da alternância sedimentar com argilito, que dificultam a exploração, suscitando pouco interesse para exploração comercial. Uma jazida explorada na década de 90 foi desativada, por falta de interesse. O mesmo ocorre em algumas jazidas existentes em Nova Olinda, Palmeirantes, Filadélfia e Babaçulândia. Casos de exploração se justificam quando as distâncias tornam-se impeditivos a compra.

Em Lagoa da Confusão e Formoso do Araguaia, no Centro-Oeste e no sudoeste do Estado, respectivamente, ocorre calcário metamórfico, pertencente à Formação Couto Magalhães. Os teores dos indicadores de qualidade do calcário são de $31 \%$ de $\mathrm{CaO}, 18 \%$ 
de $\mathrm{MgO}, 100 \%$ de PN. Nessas jazidas é comum afloramentos de calcários, o que podem não ser favoráveis para a exploração. São chamadas jazidas positivas, que chegam a atingir 30 metros de altura.

No Sudeste do estado, nos municípios de Natividade e Dianópolis existem 6 unidades de beneficiamento de calcário, que atendem demandas de agricultores do Oeste da Bahia e Sul do Piauí. A rocha é de origem sedimentar e metamórfica com afloramentos que chegam a 50 metros de altura. A rocha tem características indesejáveis, pois o afloramento indica resistência aos fatores erosivos. Assim, apresentam altos teores de sílica (impurezas), maior abrasividade (maiores gastos com manutenção de equipamentos). Os teores encontrados na região são de $27 \%$ de $\mathrm{CaO}, 16 \%$ de $\mathrm{MgO}, 89 \%$ de $\mathrm{PN}$ e $75 \%$ de PRNT.

\subsection{EQUILÍBRIO QUÍMICO DE CÁLCIO E MAGNÉSIO NO SOLO}

$\mathrm{Na}$ dissolução de determinado mineral algumas etapas fundamentais são obedecidas (STUMM, 1981). Entre essas etapas é necessário que ocorra o transporte dos reagentes dissolvidos da solução para a superfície do mineral. Em seguida os solutos são adsorvidos, ocorrendo a transferência de espécies reagentes, com posterior reação química. Aí os reagentes são desprendidos da superfície do mineral e transportados massivamente para a solução.

A eficiência com que o calcário reage no solo, para promover correção da acidez, depende do teor de carbonatos, granulometria, estrutura cristalina do material, relação entre teores de cálcio e magnésio, teor de umidade e temperatura do solo (BELLINGIERI et al., 1988). O teor de carbonato é o principal indicador da qualidade do calcário, uma vez que a reação inicial de hidrólise no solo, libera íon carbonato, que reage com íons $\mathrm{H}^{+}$. A seguir, as reações do calcário no solo:

1ำ Dissolução do Calcário: $\mathrm{CaCO}_{3}\left(\mathrm{MgCO}_{3}\right)+\mathrm{H}_{2} \mathrm{O} \leftrightarrow \mathrm{Ca}^{2+}+\mathrm{CO}_{3}{ }^{2-}\left(\mathrm{Mg}^{2+}+\mathrm{CO}_{3}{ }^{2-}\right)$

$2^{\circ}$ Dissociação do Carbonato: $\mathrm{CO}_{3}{ }^{2-}+\mathrm{H}_{2} \mathrm{O} \leftrightarrow \mathrm{HCO}_{3}{ }^{-}+\mathrm{HO}^{-}\left(\mathrm{Kb}_{1}=2,2 \times 10^{-4}\right)$

3o Dissociação do Bicarbonato: $\mathrm{HCO}_{3}{ }^{-}{ }^{-} \mathrm{H}_{2} \mathrm{O} \leftrightarrow \mathrm{H}_{2} \mathrm{CO}_{3}+\mathrm{HO}^{-}\left(\mathrm{Kb}_{2}=2,4 \times 10^{-8}\right)$

4ํNeutralização da Acidez Ativa: $\mathrm{HCO}_{3}{ }^{-}+\mathrm{H}^{+} \leftrightarrow \mathrm{H}_{2} \mathrm{CO}_{3} \leftrightarrow \mathrm{H}_{2} \mathrm{O}+\mathrm{CO}_{2} \uparrow$ 5ํ Neutralização do Alumínio: $\mathrm{Al}_{3}{ }^{+}+3\left(\mathrm{OH}^{-}\right) \longleftrightarrow \mathrm{Al}(\mathrm{OH})_{3} \downarrow$

Na primeira reação de dissolução, nota-se que o carbonato é uma base fraca, pelo valor apresentado na constante de ionização $\left(\mathrm{Kb}_{1}\right)$. Na dissolução da calcita e do bicarbonato têm-se as constantes de equilíbrio das equações ( $\mathrm{Kcal} \mathrm{e} \mathrm{KHCO}_{3}{ }^{-}$). 
Numa comparação entre a solubilidade em água de compostos formados com cálcio, o nitrato de cálcio (19\% Ca) necessita de 1 litro de água para a dissolução de $1 \mathrm{~kg}$ do produto. Já, o carbonato de cálcio precisa de $66.000 \mathrm{~L} \mathrm{~kg}^{-1} \mathrm{CaCO}_{3}$. Já o cálcio na forma oxídica precisa de $770 \mathrm{~L} \mathrm{~kg}^{-1} \mathrm{CaO}$. Assim, a solubilidade de $\mathrm{CaCO}_{3}$ e $\mathrm{MgCO}_{3}$ em água é $0,014 \mathrm{~g} \mathrm{~L}^{-1}$ e $0,106 \mathrm{~g} \mathrm{~L}^{-1}$ (BLANKENAU, 2007).

O equilíbrio nas reações químicas é alcançado, quando a razão das concentrações dos reagentes e produtos é constante. A maioria das reações e processos químicos acontece em $\mathrm{H}_{2} \mathrm{O}$. A estabilidade ou o equilíbrio de cálcio e magnésio é influenciado pelo $\mathrm{pH}$ do solo. Assim, solos com $\mathrm{pH}$ ácido os compostos silicatos, aluminossilicatos, sulfatos e carbonatos de $\mathrm{Ca}$ e $\mathrm{Mg}$ são solúveis, mas relativamente instáveis. Contudo, em solos alcalinos, portanto com pH elevado, os carbonatos são estáveis, como é possível observar nos equilíbrios que seguem:

$\begin{array}{ll}\mathrm{CaCO}_{3} \text { (calcita) }+2 \mathrm{H}^{+} \longleftrightarrow \mathrm{Ca}^{2+}+\mathrm{CO}_{2}(\mathrm{~g})+\mathrm{H}_{2} \mathrm{O} ; & \log K^{0}=9,74 \\ \mathrm{MgCa}\left(\mathrm{CO}_{3}\right)_{2} \text { (dolomita) }+4 \mathrm{H}^{+} \longleftrightarrow \mathrm{Mg}^{2+} \mathrm{Ca}^{2+}+2 \mathrm{CO}_{2}(\mathrm{~g})+2 \mathrm{H}_{2} \mathrm{O} ; & \log K^{0}=18,46\end{array}$

O $\log K^{0}$ (constante de equilíbrio) expressa a atividade e não a concentração dos produtos e dos reagentes envolvidos na reação química. A reação de dissolução da calcita fica assim:

$9,74=\log \left[\left(\mathrm{Ca}^{2+}\right)\left(\mathrm{CO}_{2}\right) /\left(\mathrm{H}^{+}\right)\right] \Longrightarrow 9,74=\log \left(\mathrm{Ca}^{2+}\right)+\log \left(\mathrm{CO}_{2}\right)-2 \log \left(\mathrm{H}^{+}\right) \Longrightarrow$

$9,74=\log \left(\mathrm{Ca}^{2+}\right)+\log \left(\mathrm{CO}_{2}\right)+2 \mathrm{pH} \Longrightarrow \log \left(\mathrm{Ca}^{2+}\right)=9,74-\log \left(\mathrm{CO}_{2}\right)-2 \mathrm{pH}$

Deduz-se que quanto mais alcalino for o solo e maior a pressão de $\mathrm{CO}_{2}$, menor será a concentração de Ca solúvel. Nessas condições a calcita é mais estável e solúvel em solo ácido. Como a pressão do $\mathrm{CO}_{2}$ é de 0,00038 atm na atmosfera, $\log \left(\mathrm{CO}_{2}\right)$ -3,4. Com isso: $\log \left(\mathrm{Ca}^{2+}\right)=13,14-2 \mathrm{pH}$

A seguir algumas reações de dissolução de Aluminossilicatos Cálcicos e Magnesianos e suas respectivas constantes de equilíbrio:

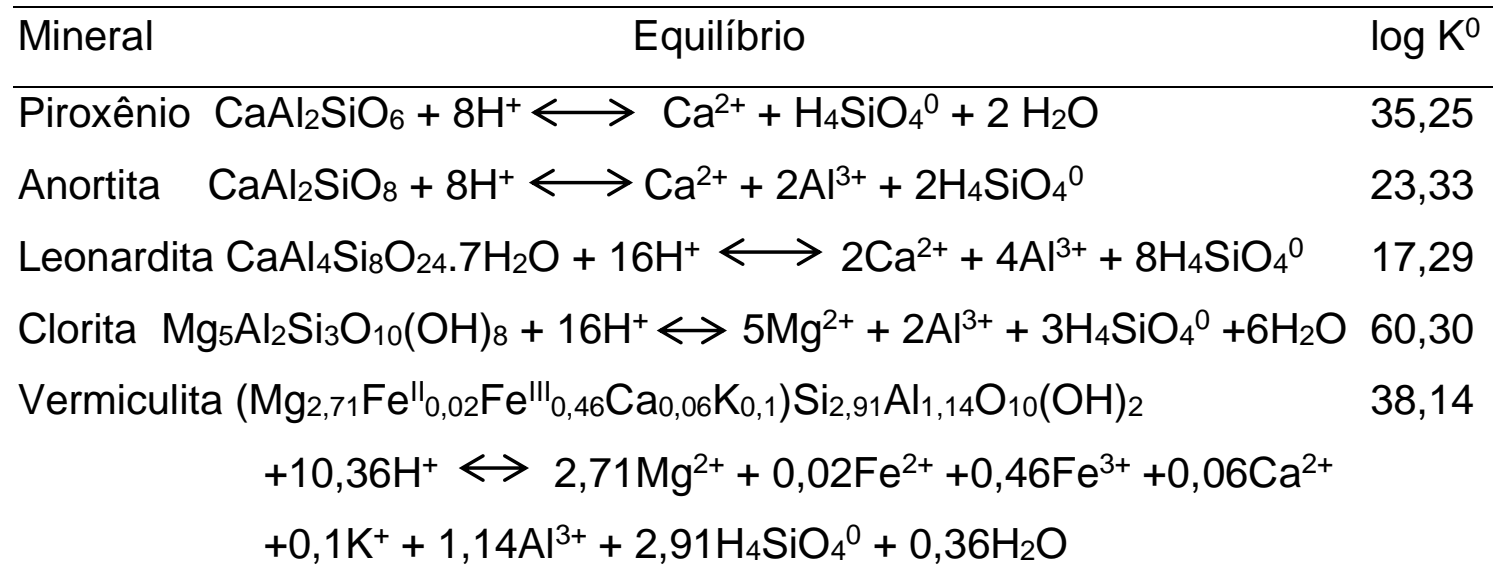


Montmorilonita $\mathrm{Mg}_{0,2}(\mathrm{Si} 3,81 \mathrm{Al} 1,71 \mathrm{Felll} 0,22 \mathrm{Mg} 0,29) \mathrm{O} 10(\mathrm{OH}) 2+$

$6,76 \mathrm{H}^{+}+3,24 \mathrm{H}_{2} \mathrm{O} \leftrightarrow 0,49 \mathrm{Mg}^{2+}+1,71 \mathrm{Al}{ }^{3+}+0,22 \mathrm{Fe}^{3+}$

$+3,81 \mathrm{H}_{4} \mathrm{SiO}_{4}{ }^{0}$

As constantes de equilíbrio maiores indicam a instabilidade de alguns desses

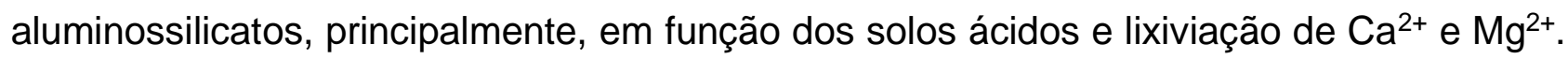
A lixiviação das bases trocáveis do solo permite a entrada de $\mathrm{H}^{+}$e $\mathrm{Al}^{3+}$ no complexo de

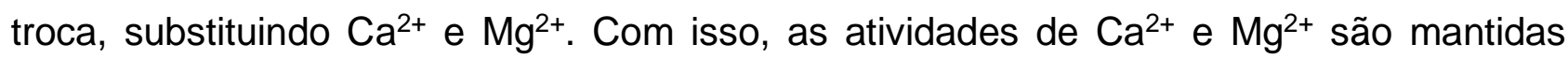
constantes. Os carbonatos e silicatos cálcicos e magnesianos, de modo geral, são instáveis e não persistem em solos e sedimentos ácidos a neutros.

Os princípios teóricos para correção de acidez dos solos com uso de carbonatos, pela elevação do $\mathrm{pH}$ e o aumento da atividade de $\mathrm{Ca}^{2+} \mathrm{e} \mathrm{Mg}^{2+}$ na solução dos solos ácidos e a reposição dessas bases no complexo de troca, são similares com o uso de silicatos e aluminossilicatos de $\mathrm{Ca}$ e $\mathrm{Mg}$. Há apenas uma redução na cinética de dissolução desses últimos em relação aos carbonatos.

\section{CONSIDERACOES FINAIS}

O estado do Tocantins é reconhecidamente um produtor agropecuário de destaque nacional e os Latossolos e Neossolos Quartzarênicos são os solos que sustentam boa parte desta produção. É nos Latossolos, que representa $21,53 \%$ dos solos do Estado, que a agricultura e a pecuária ocorrem com maior uso intensivo. Os resultados de pesquisas demostraram amplitude nos valores de fertilidade de solo, sendo os valores médios de $\mathrm{Ca}$ + Mg - 2,1 Cmolc dm3; Al - 0,5 Cmolc dm3; $\mathrm{H}+\mathrm{Al}$ - 4,2 Cmolc dm3; K - 0,2 Cmolc dm3; t2,8 Cmolc dm3; P - 14,3 mg dm3; Saturação por bases - 38,8\%; Materia Organica - 2,4\% e pH agua -5,3. Já os Neossolos Quartzarênicos predominam nas porções Norte e Leste do Estado. Os resultados demonstraram valores de $\mathrm{Ca}+\mathrm{Mg}-1,3 \mathrm{Cmolc} \mathrm{dm3;} \mathrm{Al}-$ 0,3 Cmolc dm3; H+Al - 2,16 Cmolc dm3; K - 0,2 Cmolc dm3; t-1,8 Cmolc dm3; P - 2,4 mg dm3; Saturação por bases - 39,1\%; Materia Organica - 1,1\% e pH agua - 4,8.

Quanto ao panorama de ocorrência de jazidas de calcário no Tocantins, dentre elas, destaca-se as que estão sendo exploradas comercialmente, tais como, a jazida de calcários de rocha metamórfica na região noroeste, municípios de Xambioá, Bandeirantes e Bernardo Sayao. Outra de origem metamórfica ocorre na região centro-oeste (Lagoa da confusão) e sudoeste (formoso do Araguaia). Na região sudeste (Natividade e Dianópolis) são calcários 
provenientes de rochas sedimentar e metamórfica, com PRNT em torno de $75 \%$. Os calcários de melhor qualidade foram encontrados em formoso de Araguaia com PRNT de $92 \%$.

\section{REFERENCIAS}

AMARAL, E. F.; BARDALES, N. G.; ARAÚJO, E. A.; OLIVEIRA, T. K.; FRANKE, I. L.; OLIVEIRA, C. H. A. Classificação etnopedológica dos solos dos Kaxinawas da Terra Indígena Kaxinawa do Nova Olinda, município de Feijó, Estado do Acre. Florianópolis: Anais XXXIV Congresso Brasileiro Ciência do Solo, 2013.

ARAÚJO, A. L.; ALVES, A. G. C.; ROMERO, R. E.; FERREIRA, T. O. Etnopedologia: uma abordagem das etnociências sobre as relações entre as sociedades e os solos. Ciência Rural, v.43, n.5, p. 854-860, 2013

AUDEH, S. J. S.; LIMA, A. C. R.; CARDOSO, I. M.; CASALINHO, H. D.; JUCKSCH, I. J. Qualidade do solo: uma visão etnopedológica em propriedades agrícolas familiares produtoras de fumo orgânico. Revista Brasileira de Agroecologia, v.6, n.3, p. 34-48, 2011

BARRERA-BASSOLS, N.; ZINCK, J. A. Ethnopedology: a worldwide view on the soil knowledge of local people. Geoderma, v. 111, p. 171-195, 2003. Disponível em: <http://www.sciencedirect.com/science/article/pii/S001670610200263X>. Acesso em: 15 de jan. 2015. doi: 10.1016/S0016-7061(02)00263-X.

BELLINGIERI, P. A.; ALCARDE, J. C.; SOUZA, E. C. A. Reatividade de calcários agrícolas e a relação entre teores de cálcio e magnésio. Piracicaba: Anais... ESALQ 45 (parte 2), p. 499-515, 1988.

BLANKENAU, K. Cálcio nos solos e nas plantas. Inf. Agronômicas n. 17, 2007

CAPONE, A.; SANTOS, E. R.; FERRAZ, E. C.; SANTOS, A. F.; OLIVEIRA, J. L.; BARROS, H. B. Desempenho agronômico de cultivares de girassol no sul do Estado do Tocantins. Journal of Biotechnology and Biodiversity, v. 3, n.3, p. 13-23, 2012

COELHO, F. H. F.; MARCELLINO, M. S.; DOURADO, M.; AMADO, M. V. L.; MICHELIN, L. H. F.; DOURADO, D. P. Características agronômicas do milho irrigado em função de doses crescentes de potássio. RIU, v.7, n,9, p. 147-151, 2013

COLLICCHIO, E. Zoneamento edafoclimático e ambiental para a cana-de-açúcar e as implicações das mudanças climáticas no estado do Tocantins. Tese (Doutorado em Ecologia Aplicada). Escola Superior de Agricultura "Luiz de Queiroz", Universidade de São Paulo, São Paulo. 156f, 2008.

COMISSÃO DE FERTILIDADE DO SOLO DO ESTADO DE MINAS GERAIS - CFSEMG. Recomendações para o uso de corretivos e fertilizantes em Minas Gerais : $5 a$ Aproximação / Antonio Carlos Ribeiro, Paulo Tácito Gontijo Guimarães, Vitor Hugo Alvarez V.( Eds.) Viçosa, MG: 1999. 359p. 
COLLIER, L. S.; ARAÚJO, G. P. Fertilidade do solo sob sistemas de produção de subsistência, agrofloresta e vegetação remanescente em Esperantina - TO. Floram, v.17, n. 1 , p. 12-22, 2010

EMPRESA BRASILEIRA DE PESQUISA AGROPECUÁRIA (Embrapa). Sistema Brasileiro de Classificação de Solos. 2. ed. Rio de Janeiro: Embrapa/Centro Nacional de Pesquisa de Solos, 2006.

FAGERIA, N. K.; MOREIRA, A.; CASTRO, C. Resposta da soja à adubação fosfatada em Latossolo do Estado do Tocantins. Brasília: Resumos da XXXI Reunião de Pesquisa de Soja da Região Central do Brasil, 2010.

FERREIRA, C. A. Gênese de "Latossolos acinzentados" em topossequênacia de Latossolos das chapadas do Alto Vale do Jequitinhonha. Dissertação de Pós-Graduação. Univ. Fed. Vales do Jequitinhonha e Mucuri, Diamantina. 84f, 2008,

FLORES, R. A.; URQUIAGA, S.; ALVES, B. J. R.; COLLIER, L. S.; ZANETTI, J. B.; PRADO, R. M. Nitrogênio e idade de corte na qualidade da biomassa de capim-elefante para fins agroenergéticos cultivado em Latossolo. Semina: Ciências Agrárias, v.34, n.1, p. $17-136,2013$

GAMA, J. R. F. N.; CARVALHO, E. J. M.; RODRIGUES, T. E.; VALENTE, M. A. Solos do Estado do Pará. In: CRAVO, M. S.; VIÉGAS, I. J. M.; BRASIL, E.C. Recomendações de adubação e calagem para o estado do Pará. Belém, Embrapa Amazônia Oriental, p.1929. 2007.

HAIDAR, R. F.; FAGG, J. M. F.; PINTO, J. R. R.; DIAS, R. R.; DAMASCO, G.; SILVA, L. C. R.; FAGG, C. W. Forestas estacionais e áreas de ecótono no estado do Tocantins, Brasil: parâmetros estruturais, classificação das fitofisionomias florestais e subsídios para conservação. Acta Amazônica, 43, n. 3, p. 261-290, 2013

INSTITUTO BRASILEIRO DE GEOGRAFIA E ESTATÍSTICA (IBGE), Estado do Tocantins: Pedologia, Mapa Exploratório de Solos. bCIMd, 1aㅡ Edição. 2007a.

INSTITUTO BRASILEIRO DE GEOGRAFIA E ESTATÍSTICA (IBGE), Estado do Tocantins: Geologia. bCIMd, 1aㅡ Edição. 2007b.

KELLOG, C.E. Preliminary suggestions for the classification and nomenclature of great soil groups in tropical and equatorial regions. Common. Bur. Soil Sci. Tech. Comm., v.46, p. $76-85,1949$

MARCELINO, M. S.; CORRÊA, M. L. T. Efeitos da calagem e da adubação orgânica sobre a adsorção de Zn e Cu em dois solos do Estado do Tocantins. Palmas, XVII Jornada de Iniciação Científica. 2010

MATA, J. F.; SILVA, R. R.; FONTES, M. P. F.; ERASMO, E. A. L.; FARIAS, V. L. S. Análise mineralógica, granulométrica e química, em solos de ecótonos do sudoeste do Tocantins. Rev. Brasileira de Tecnologia Aplicada nas Ciências Agrárias, v.4,n.2, p. 152-175, 2011 
MATOS, L. V.; KER, J. C.; CARDOSO, I. M.; LANI, J. L.; SCHAEFER, C. E. G. R. O conhecimento local e a etnopedologia no estudo dos agroecossistemas da comunidade quilombola de Brejo dos Crioulos. Sociedade \& Natureza, v.26, n. 4, p. 497-510, 2014

MENDONÇA, G. V. Análise florístico-estrutural e relações com o ambiente em área de ecótono floresta estacional-cerrado sensu stricto no estado do Tocantins. Dissertação (Mestrado em Ciências Florestais), UnB, Brasília. 96f. 2012,

MUGGLER, C. C.; SOBRINHO, F. A. P.; MACHADO, V. A. Educação em solos: princípios, teoria e métodos. Revista Brasileira Ciência do Solo, v.30, p. 733-740, 2006

NEGREIROS NETO, J. V.; SANTOS, A. C.; SANTOS, P. M.; SANTOS, T. M.; FARIA, A. F. G. Atributos físicos de solos sob a consorciação gramíneas-leguminosas no Norte do Estado do Tocantins. Revista Engenharia na Agricultura, v.18, n.2, p. 140-150, 2010

NEGREIROS NETO, J. V.; SANTOS, A. C.; GUARNIERI, A.; SOUZA, D. J. A. T.; DACONCH, D. J.; DOTTO, M. A.; ARAÚJO, A. S. Variabilidade espacial de atributos físico-químicos de um Latossolo Vermelho-Amarelo distrófico em sistema plantio direto. Semina: Ciências Agrárias, v.35, n.1, p. 193-204, 2014

OLIVEIRA, G. C. Solos da Região dos Cerrados: Reconhecimento na paisagem, potencialidades e limitações para uso agrícola. Monografia de Pós - Graduação. Universidade Federal de Lavras, Lavras. 69f. 2009,

PRADO, H. Pedologia fácil: aplicações na agricultura. Piracicaba, 105p. 2007.

RHEINHEIMER, D. S.; KAMINSKI, J.; LUPATINI, G. C.; SANTOS, E. J. C. Modificações em atributos químicos de solos arenosos sob plantio direto. Revista brasileira de Ciência do Solo, v.22, p. 713-721, 1998

RODRIGUES, T.E. Solos da Amazônia. In: ALVAREZ V., V.H.; FONTES, L.E.F. \& FONTES, M.P., eds. O solo nos grandes domínios morfoclimáticos do Brasil e o desenvolvimento sustentado. Viçosa, MG, SBCS/UFV/DPS, 1996. p.19-60.

ROTILI, E. A. Eficiência e resposta quanto ao uso de nitrogênio e fósforo de cultivares de arroz em solos de várzea irrigada e terras altas no sul do Estado do Tocantins. Dissertação (Mestrado Produção Vegetal), UFT, Gurupi. 102f. 2009.

SÁ, M. F. M. Os solos dos Campos Gerais. In: Patrimônio Natural dos Campos Gerais do Paraná. 1 Ed. Ponta Grossa: Editora UEPG, 2007. cap. 6, p. 73-83.

SABOYA, R. C. C.; CHAGAS JR., MONTEIRO, F. P. R.; SANTOS, G. R.; ERASMO, E. A. L.; CHAGAS, L. F. B. Fungos micorrízicos arbusculares afetando a produção de mudas de pinhão-manso na região Sul do Estado do Tocantins, Brasil. Revista Ceres, v.59, n.1, p. 142-146, 2012

SANTANA, H. M. P.; LACERDA, M. P. C.; BARROS, M. A.; BARBOSA, I. O. Unidades pedoambientais da Região de Santa Tereza, Estado do Tocantins. Pesquisa Agropecuária Tropical, v.40, n.1, p. 8-19, 2010 
SÉGALEN, P. Les sols ferrallitique setleur repartition géographique. $1^{\text {a }}$ ed. Paris, editionsdel'ORSTOM. Collection Étudeset Théses. 1994. 197p.

SEPLAN, Secretaria de Planejamento e Meio Ambiente do Tocantins. Diretoria de Zoneamento Ecológico-Econômico (DZE). Base de dados geográficos do Tocantins. Palmas, 2007.

SILVA, R. B.; SANTOS, A. C.; SILVA, J. E. C.; OLIVEIRA, L. B. T.; ARAÚJO, A. S. Diagnóstico do solo em áreas de ocorrência de capim dourado na Região do Jalapão, Estado do Tocantins. Amazônia: Ci. \& Desenv. 2010; 6(11).

SILVA, A. K. T.; GUIMARÃES, J. T. F.; LEMOS, V. P.; COSTA, M. L.; KERN, D. C. Mineralogia e geoquímica de perfis de solo com Terra Preta Arqueológica de Bom Jesus do Tocantins, sudeste da Amazônia. Acta Amazônica, v.42, n. 4, p. 477-490, 2012

SOUZA, L. S. Adequação do uso das terras e qualidade física dos solos em pastagens no Distrito Federal. Monografia (Graduação em Agronomia). Universidade de Brasília, Brasília. 63f. 2012.

STUMM, W. Chemistry of the solid-water interface: Processes at the mineral-water and particle-water interface in natural systems. lohn Wiley \& Sons, New York, NY, 1981.

TAVARES, L. F. S.; CANDEIRO, C. R. A. Região de fronteiras: fauna e flora em Itaguatins, norte do estado do Tocantins. Brazilian Geographical Journal: Geociences and Humanities research medium, v.3, n.2, p. 513-519, 2012

TAVARES, A. K. Caracterização etnopedológica de terras agrícolas com agricultores familiares dos municípios de Antonina e Morretes-PR. Dissertação (Mestrado em Ciência do Solo). Univ. Federal do Paraná, Curitiba. 76f. 2012.

VALE JÚNIOR, J.F. et al. Etnopedologia e transferência de conhecimento: diálogos entre os saberes indígena e técnico na terra indígena Malacheta, Roraima. Revista Brasileira de Ciências do Solo, v.31, p. 403-412, 2007. Disponível em: $<$ http://www.scielo.br/scielo.php?script=sci_arttext\&pid=S0100$06832007000200023 \&$ Ing=en\&nrm=iso\&tIng=pt>. Acesso em: 20 dezembro, 2014. doi: $10.1590 / \mathrm{S} 0100-06832007000200023$.

MELO, A.V.; AFFÉRRI, F. S.; DOTTO, M. A.; PELUZIO, J. M.; SANTOS, G. R.; CARVALHO, E. V. Reação de híbridos de milho à Curvularia ssp, sob dois níveis de adubação com nitrogênio, no Sul do Tocantins. Scientia agraria, v.11, n. 2, p. 149-154, 2009

VILELA, L. C.; SANTOS, A. C.; BARRETO, P. M.; BRITO, S. S.; SILVA, J. E. C.; OLIVEIRA, L. B. T. Propriedades químicas de Latossolo Vermelho em função da aplicação de gessagem e calagem. Revista Acadêmica : Ciências Agrárias e Ambientais, v.8, n.1, p. 19-27, 2010 